\title{
Environmental Protection for Sustainability
}

\author{
Michael A. Gonzalez
}

Published online: 11 April 2014

(c) Springer-Verlag Berlin Heidelberg (outside the USA) 2014

It is amazing how all the events and activities in our lives are interconnected. As a young boy growing up in El Paso, Texas, I was exposed to many aspects of life and even had family relatives from all social classes. This never bothered me, because they were family and it made me aware there was a huge and vastly different world beyond the street that I lived on. While I could see the apparent differences between these social classes, it never really occurred to me there were also differences that occurred under the surface of what was seen. You are probably wondering why I am beginning this editorial with this, but as you read, you will see that these experiences and events in my life have shaped me as a man, a son, and a father. These experiences have also contributed to my approach as a researcher at the U.S. Environmental Protection Agency (EPA) and the reason why I wanted to share the research in this special feature issue with you.

Growing up in a city on the United States border with Mexico really opened up my eyes to the stark differences between the two countries. Not only in the style of living and the culture, but also in daily things we take for granted. Such as the air we breathe, the water we drink and play in, and to the land we live on. Of course, these are issues that affect any city, but in my opinion, they are heightened when it occurs in a metropolis that spans two countries and one border. Additionally, the two cities are tied at the hip, since they are geographically close, in this case separated by the Rio Grande, and any environmental event that occurs in one city is more than likely felt in the other.

\section{A. Gonzalez ( $\square)$}

United States Environmental Protection Agency, Office of

Research and Development, National Risk Management

Research Laboratory, Cincinnati, OH, USA

e-mail: gonzalez.michael@epa.gov
I can remember driving to school at the University of Texas-El Paso every morning and seeing a thick yellow layer of smog and pollution that blanketed Juarez, Mexico and extended into a portion of El Paso. I can also remember the dirt streets in the Colonias in Juarez, Mexico with tremendous amounts of trash and the erosion from the runoff from the rains (when we did get rain), to the lack of water in both cities and being told by the City of El Paso what days we could use water outside. This was an initial effort the city was making in hopes of extending the available water resources within the region.

These memories of El Paso, as well as many others, are so fresh in my memory, even to this day, I can still remember so vividly one activity I did with my grandparents every other weekend that really put into context the concept of environmental protection, even though I did not know it was doing so at the time. We had family that lived in a Colonia in Juarez, Mexico; my uncle, John, his wife Patty, and their son, Pepe, my cousin. While John was a U.S. citizen, he chose to live in Mexico with his wife and their extended family. He did this, because it made him happy. I remember going to their house for the first time when I was about 9 years old. When I first saw where they lived, I was really surprised not from what I saw, but the fact that it was not the same as our house. Their house had cement and dirt floors, electricity was provided from a generator, and from what I remember their city services were very limited (water and sewer). I remember their street was not paved and garbage was strewn everywhere throughout the neighborhood. But, it was my Uncle's home and he loved it. I too loved going there to visit my family and spend time with my cousin. But, the fact that they lived in so drastically different conditions made me realize that not everyone lived at the same standard of living as we did in the States. To help them out, my paternal grandparents 
would bring them water for drinking and cooking, since access to drinking water was limited or non-existent. We would also bring groceries and diesel fuel for the generator. It was not that they could not afford it, but there was limited availability of fuel and the grocery stores did not always have stock and their prices were much higher than in the U.S. My grandparents did this, because they were our family and they wanted to make sure they had the daily necessities to sustain a higher and healthier quality of life.

It was after seeing this that I began to appreciate more and more what my parents provided to me everyday, as well as to not take for granted the environment I lived in. To this day, I show my children what they should be appreciative of and do what they can to help out others who do not have the same things we do.

As I left college and moved on to graduate school at the University of Florida, I began to put into practice my desire to contribute to protecting the environment. I did this through what I knew best chemistry, and my passion for it. During this time, I learned how to design chemical reactions that were greener and how to apply them to have a minimal impact on the environmental and human health. This then led me to the next step in my career path, becoming a researcher at the U.S. EPA in Cincinnati, Ohio.

The U.S. Environmental Protection Agency was created as a result of decades of man-made activities that had very little regard for their effect on the water, air, and land. If you look at the evolution of the Agency, it has gone from one focused primarily on regulation, enforcement, and control at its point of creation, to an Agency that began to include the concepts of pollution prevention and now to an Agency that is incorporating the practice of Sustainability in its mission.

In mid 2010, the U.S. Environmental Protection Agency's (EPA) Office of Research and Development (ORD) undertook the task of restructuring its research portfolio to establish the practice of Sustainability at its foundation. This restructuring demonstrated ORD was committed to achieving its mission of "protecting and safeguarding human health and the environment," but also toward the direction of becoming proactive to the prevention of environmental and human health challenges. This restructuring resulted in the formation of six National Research
Programs, each being supportive of EPA national priorities. The six programs include: Air, Climate, and Energy (ACE), Chemical Safety for Sustainability (CSS), Sustainable and Healthy Communities (SHC), Safe and Sustainable Water Resources (SSWR), National Homeland Security, and Human Health and Risk Assessment.

With this integration of Sustainability into its mission, operation, and practice, the goal is to become as proactive to environmental and human health challenges as we had been reactive. As we examine the challenges our nation and our international partners face, we can conclude many are the result of man-made activities. These activities have the potential to generate significant environmental and human health impacts throughout their entire life cycle. With this potential for impact, it is evident a sustainable and holistic approach to design, manufacturing, use/reuse, and management can contribute significantly to addressing the current and any future environmental and human health impacts caused by these man-made activities.

In this special feature issue, the authors and I bring to you diverse state-of-the-art contributions from ORD's research with the potential to help lead us down the path to becoming more sustainable. With research topics spanning the six National Research Programs, this demonstration of next-generation and innovative thinking research will help us avoid the environmental and human health challenges of the past and focus on developing a societal and corporate mindset to consider the life cycle of an activity prior to performing that activity.

I am very thankful to all my colleagues for their scientific passion, patience, and valuable contributions to this special feature issue on Sustainability Research at the U.S. Environmental Protection Agency. I am also very grateful to the staff at Clean Technologies and Environmental Policy for their support. I also want to thank Dr. Subhas K. Sikdar for giving me the opportunity for the professional realization of this issue.

In addition, remember....

"Nothing great in the world has ever been accomplished without passion."

-Hebbel 